\title{
Implementation of rectangular slit-inserted ultra-wideband tapered slot antenna
}

\author{
Sun-Woong Kim ${ }^{1}$ and Dong-You Choi ${ }^{2^{*}}$
}

*Correspondence: dychoi@
chosun.ac.kr
${ }^{2}$ Department of Information
and Communication
Engineering, Chosun
University, Gwangju, Korea
Full list of author information
is available at the end of the
article

article

\begin{abstract}
In this paper, a tapered slot antenna capable of ultra-wideband communication was designed. In the proposed antenna, rectangular slits were inserted to enhance the bandwidth and reduce the area of the antenna. The rectangular slit-inserted tapered slot antenna operated at a bandwidth of $8.45 \mathrm{GHz}$, and the bandwidth improved upon the basic tapered slot antenna by $4.72 \mathrm{GHz}$. The radiation pattern of the antenna was suitable for location recognition in a certain direction owing to an appropriate $3 \mathrm{~dB}$ beam width. The antenna gain was analyzed within the proposed bandwidth, and the highest gain characteristic at $7.55 \mathrm{dBi}$ was exhibited at a $5-\mathrm{GHz}$ band. The simulation and measurement results of the proposed tapered slot antenna were similar.
\end{abstract}

Keywords: Ultra wideband, Tapered slot antenna, Rectangular slit, Directivity radiation pattern

\section{Background}

The number of applications for wireless communication systems are increasing because of interest from industry, the medical and scientific communities, and various others. Accordingly, in the academic field, many studies on antennas types such as wideband, multiband, and compact are being conducted.

In this paper, an antenna capable of wideband communication is proposed. Possible antenna structures include bow-tie, log-periodic, spiral, fractal, and tapered slot. The antennas with these structures are applied to various wireless communication systems depending on the antennas' shape and characteristics, and particularly in the UWB communication system (Kim et al. 2015; Yoon et al. 2015).

For the UWB wireless communication system, the allowed limit was defined as the frequency band of 3.1-10.6 GHz by FCC (Federal Communication Commission) in USA, and it has to satisfy the $25 \%$ of fractional bandwidth and the frequency bandwidth of $500 \mathrm{MHz}$ or higher (Choi et al. 2014).

UWB technology has many applications including penetrating radar, nondestructive testing radars for civil engineering, precision location tracking systems, and medical and wireless communications (Notice of Inquiry in the Matter of Revision of Part 15 of the Commission's Rules Regarding Ultra-Wideband Transmission Systems; Garg et al. 2001; Deng et al. 1999; McKinney et al. 2008). 
The antenna proposed in this paper is a tapered slot antenna. The tapered slot antenna is a directive antenna, which can recognize a location in a certain direction, and has many applications including measurement systems, vehicular radar, and through-wall radar.

In this paper, a tapered slot antenna is designed and proposed. The antenna has a $3 \mathrm{~dB}$ beam width, high gain, and directive characteristics, which are appropriate for reducing the area of the antenna and for location recognition. The bandwidth was improved by inserting rectangular slits in the radiator of the antenna.

This paper is organized as follows. In "Materials and methods" section, the tapered slot antenna is designed and proposed. In "Results and discussion" section, the characteristics of antenna are analyzed through simulation and measurement. In "Conclusions" section, a conclusion is provided.

\section{Methods}

The tapered slot antenna can be easily fabricated because of its dimensional tolerance of low precision and infinite bandwidth. Nevertheless, a desired bandwidth can be induced by changing the physical size of the radiator and using various design technologies. The design and simulation analysis of the proposed antenna is obtained by using an HFSS of Ansys Co.

A wide bandwidth was induced by inserting rectangular slits in Structure-1, as shown in Fig. 1a. The structure of the proposed antenna is shown in Fig. 1b (Fei et al. 2011; He et al. 2014). The proposed antenna was improved wide impedance bandwidth by inserting rectangular slits in the radiator of the antenna, and the area of the antenna is achieved a reduction ratio of $15.5 \%$. However, the proposed antenna was satisfied with the commercial UWB band.

The proposed tapered slot antenna was fabricated on an FR-4 substrate with a specific inductive capacity of 4.7, a loss tangent of 0.019 , and a thickness of $1.6 \mathrm{~mm}$ (Kim et al. 2015). Once the aperture size of the antenna is determined by operating frequency, the antenna should be able to transmit a signal at its longest wavelength. To do this from a dielectric substrate, Eq. (1) must be satisfied:

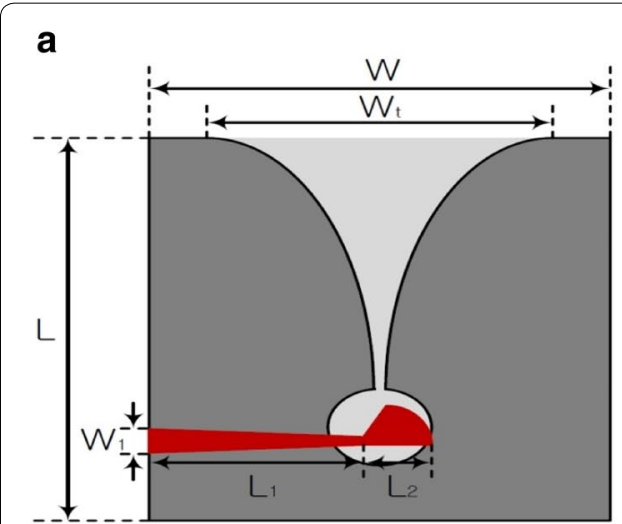

b

Fig. 1 Structure of proposed tapered slot antenna. a Structure-1. b Structure-2

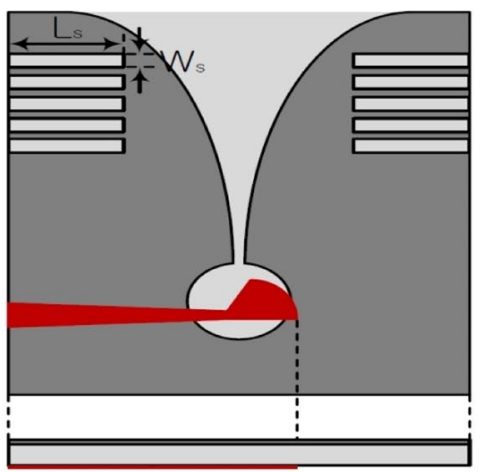




$$
W_{t}=\frac{\lambda_{g}}{2}=\frac{C}{2 f_{r} \sqrt{\varepsilon_{r}}}
$$

where $\lambda_{g}$ is the guide wavelength $(\mathrm{m}), C$ is the speed of light $(\mathrm{m} / \mathrm{s})$, and $\varepsilon_{r}$ is the dielectric constant. In Eq. (1), the tapered slot antenna operates as a resonance antenna at a low frequency, and is determined by the physical size of the operating frequency $f_{r}$ and the value of $\varepsilon_{r}$ used in the fabrication of the antenna. Therefore, by using Eq. (1), the total size of the tapered slot antenna can be determined for operation in a desired bandwidth. The fabricated antenna and its dimensions are shown in Fig. 2 and Table 1 Kim (2013).

$W$ and $L$ are the length and width of the proposed antenna, and $W_{t}$ is the aperture width of the tapered slot. $W_{1}, L_{1}$, and $L_{2}$ are the lengths and width of the impedance converter. $W_{s}$ and $L_{s}$ are the width and length of the rectangular slit for the proposed tapered slot antenna (Choi et al. 2014; Shrestha et al. 2013).

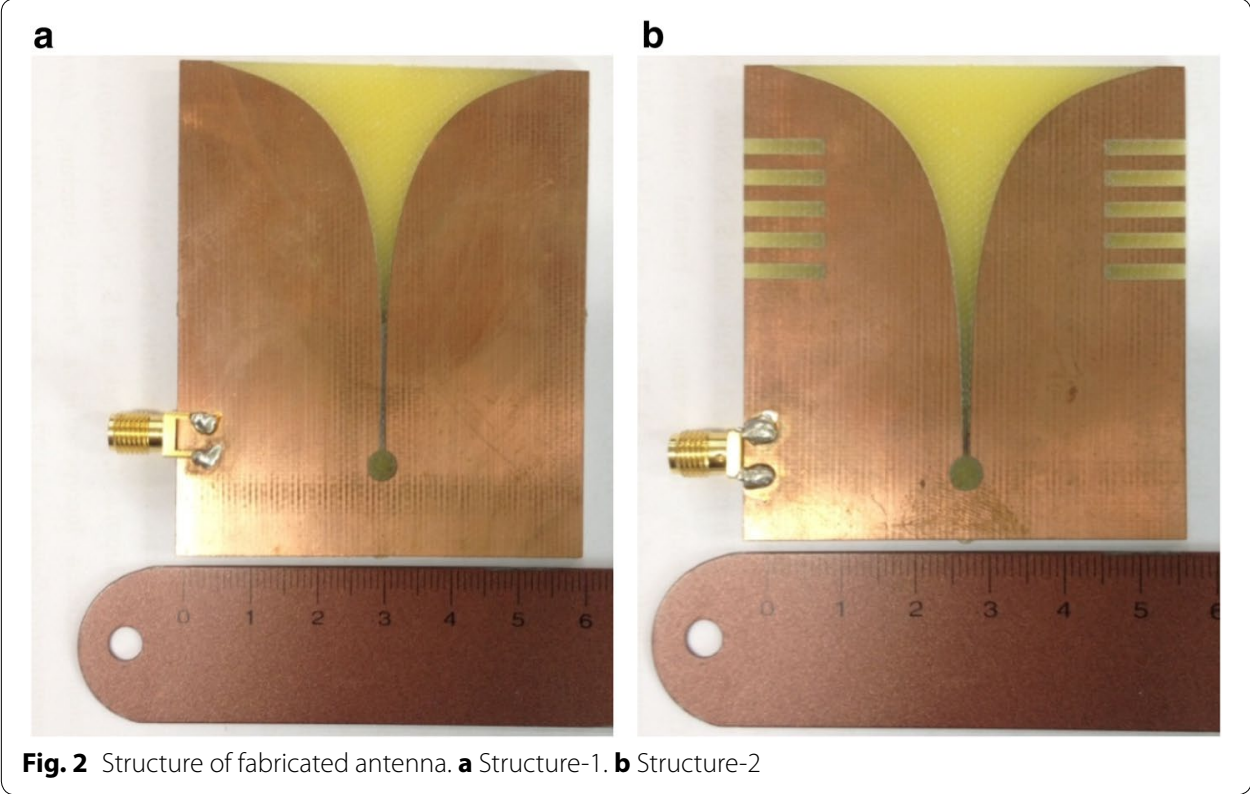

Table 1 Dimensions of proposed antenna ( $\mathrm{mm})$

\begin{tabular}{llc}
\hline Antenna & Structure-1 & Structure-2 \\
\hline$W$ & 60 & 58.2 \\
$L$ & 70 & 61 \\
$W_{t}$ & 51 & 52 \\
$W_{1}$ & 3 & 3 \\
$L_{1}$ & 28 & 28 \\
$L_{2}$ & 7.5 & 7.4 \\
$W_{s}$ & - & 2 \\
$L_{s}$ & - & 10.7 \\
\hline
\end{tabular}




\section{Results and discussion}

\section{Analysis of matching characteristics and antenna bandwidth}

The reflection coefficient $\Gamma$ is the amount of signal reflection by impedance mismatch that occurs between the source and antenna during the operation of an antenna in a single-port circuit. The optimal reflection coefficient is $\Gamma=0$, and the usual impedance bandwidth of the antenna is defined as $-10 \mathrm{~dB} \mathrm{~S}_{11}$ and VSWR $\leq 2$. This means that approximately $11 \%$ of the input power is reflected (Chang 2000).

Figure 3 shows the results of an impedance bandwidth simulation for Structure- 1 and Structure- 2 of the proposed tapered slot antenna.

In the simulation results shown in Fig. 3, the impedance bandwidth of Structure-1 satisfied the requirements of $-10 \mathrm{~dB} \mathrm{~S}_{11}$ and VSWR $\leq 2$ in the low-frequency bandwidth of 2.33-6.46 GHz and high frequency-bandwidth of 8.84-11.32 GHz. However, the middle-frequency bandwidth was suppressed. By contrast, in the case of a rectangular slitinserted tapered slot antenna, the 7.2 GHz bandwidth satisfied the requirements for -10 $\mathrm{dB} \mathrm{S}_{11}$ and VSWR $\leq 2$ in the 3.64-10.84 GHz bandwidth, and improvement was seen in the middle-frequency bandwidth of Structure- 1 .

The improved impedance bandwidth was observed through the increase of rectangular slits, as show in Fig. 4.
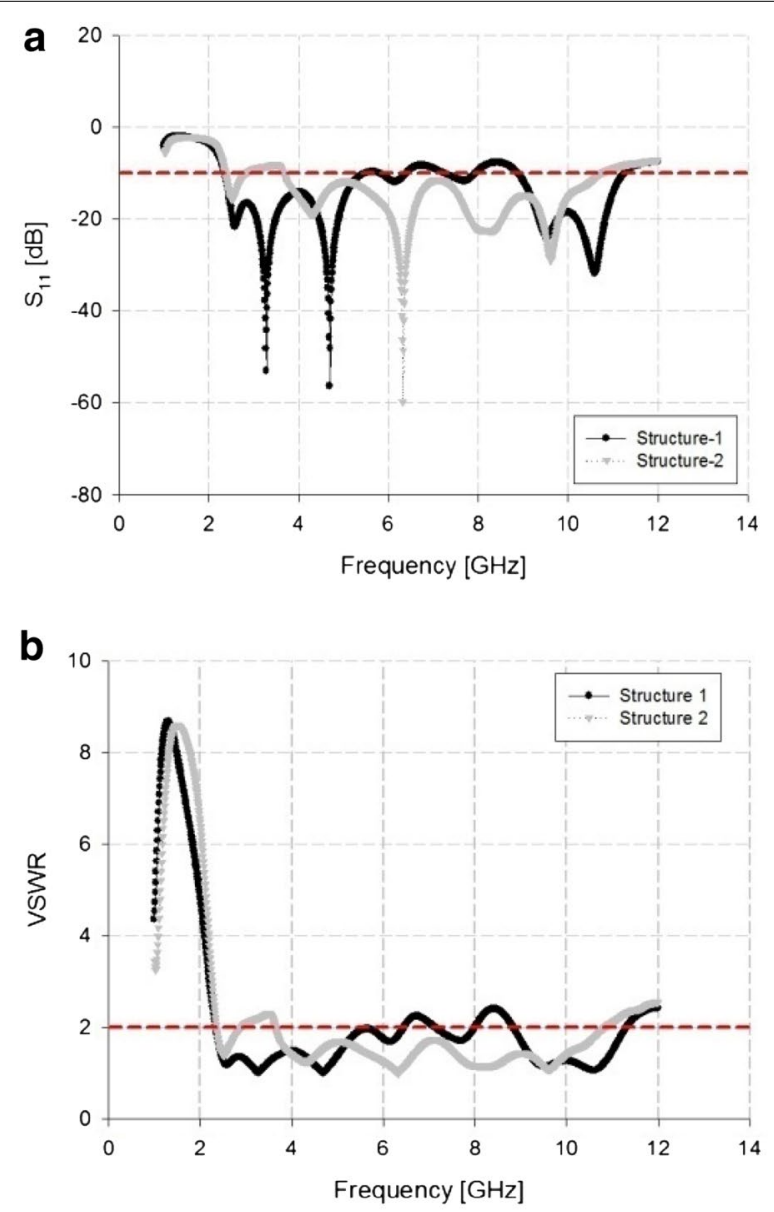

Fig. 3 Results of impedance bandwidth simulation. a $\mathrm{S}_{11}$. bVSWR 

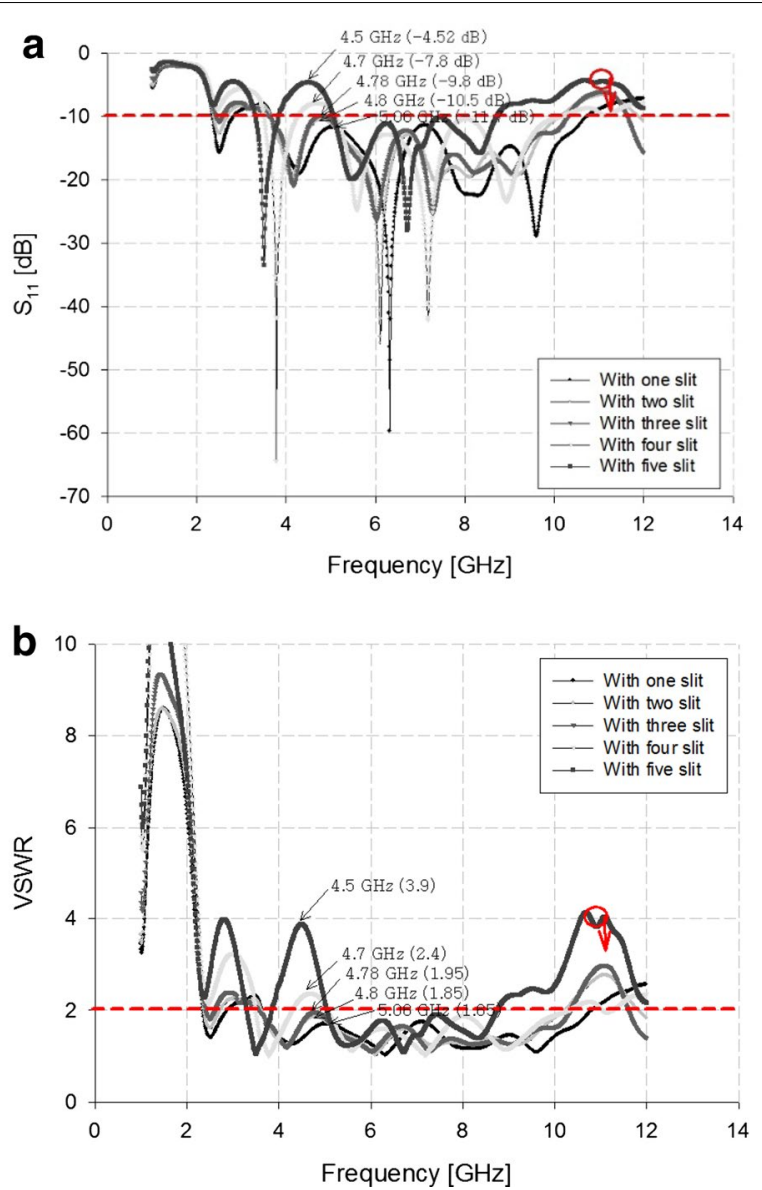

Fig. 4 Simulation analysis through the increase of the rectangular slit. a $S_{11}$. b VSWR

In the simulation results show in Fig. 4, a steady matching characteristics are obtained due to the insertion of rectangular slits which result in increase of impedance bandwidth.

The impedance bandwidth of the proposed antenna was measured by Network Analyzer (N5230A) of Agilent Co. Pozar (2012). The results of fabricating the tapered slot antenna using the impedance bandwidth measurement results is shown in Fig. 5.

In the measurement results shown in Fig. 5, Structure-1 showed a bandwidth of 3.73 GHz by satisfying $-10 \mathrm{~dB} \mathrm{~S}_{11}$ and VSWR $\leq 2$ in the $3.26-6.99 \mathrm{GHz}$ bandwidth range. While satisfying $-10 \mathrm{~dB} S_{11}$ and VSWR $\leq 2$ in the $3.55-12 \mathrm{GHz}$ bandwidth similarly, Structure- 2 achieved a bandwidth of $8.45 \mathrm{GHz}$. The simulation and measurement results are similar, and the measurements show that the bandwidth of $4.72 \mathrm{GHz}$ improved in Structure-2 compared with Structure-1.

\section{Analysis of antenna gain and radiation pattern}

One important antenna characteristic is how much the antenna can focus and radiate radio waves in a certain direction. In the E-plane $(x-z)$ and H-plane $(x-y)$ of the proposed tapered slot antenna, the radiation pattern and $3 \mathrm{~dB}$ beam width were analyzed. The analysis of the simulation is shown in Fig. 6. 

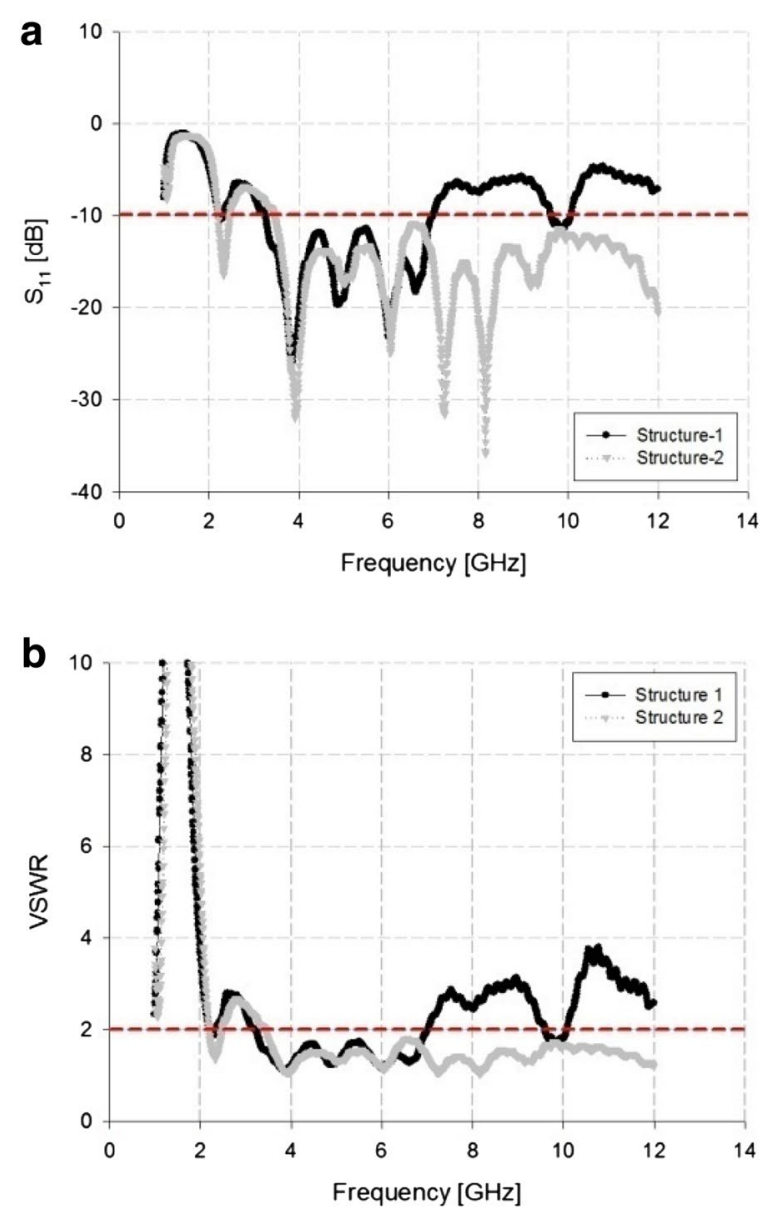

Fig. 5 Measurement results for impedance bandwidth. a $\mathrm{S}_{11}$. b VSWR

In the simulation results of Fig. 6 for the E-plane and H-plane, the $3 \mathrm{~dB}$ beam width was $130^{\circ}$ and $77^{\circ}$ in the $3 \mathrm{GHz}$ band. For Structure-1, the $3 \mathrm{~dB}$ beam width was $85^{\circ}$ and $77^{\circ}$ in the $4 \mathrm{GHz}$ band, and $78^{\circ}$ and $65^{\circ}$ in the $5 \mathrm{GHz}$ band. For Structure-2, the beam width was $140^{\circ}$ and $75^{\circ}$ in the $3 \mathrm{GHz}$ band, $95^{\circ}$ and $110^{\circ}$ in the $4 \mathrm{GHz}$ band, $84^{\circ}$ and $64^{\circ}$ in the $5 \mathrm{GHz}$ band, $62^{\circ}$ and $55^{\circ}$ in the $6 \mathrm{GHz}$ band, $55^{\circ}$ and $68^{\circ}$ in the $7 \mathrm{GHz}$ band, $42^{\circ}$ and $90^{\circ}$ in the $8 \mathrm{GHz}$ band, and $41^{\circ}$ and $85^{\circ}$ in the $9 \mathrm{GHz}$ band.

Radiation pattern measurement of the proposed antenna is measured using an antenna far-field analysis system in an anechoic chamber as mentioned in Chang (2000). The radiation pattern measurement results for the tapered slot antenna that was fabricated using these characteristics are shown in Fig. 7.

Examining the measurement results in Fig. 7, in the E-plane and H-plane, the $3 \mathrm{~dB}$ beam width was $90^{\circ}$ and $125^{\circ}$ in the $3 \mathrm{GHz}$ band for Structure- $1,75^{\circ}$ and $80^{\circ}$ in the $4 \mathrm{GHz}$ band, and $50^{\circ}$ and $75^{\circ}$ in the $5 \mathrm{GHz}$ band. For Structure-2, the beam width was $115^{\circ}$ and $128^{\circ}$ in the $3 \mathrm{GHz}$ band, $60^{\circ}$ and $123^{\circ}$ in the $4 \mathrm{GHz}$ band, $55^{\circ}$ and $84^{\circ}$ in the $5 \mathrm{GHz}$ band, $78^{\circ}$ and $58^{\circ}$ in the $6 \mathrm{GHz}$ band, $87^{\circ}$ and $80^{\circ}$ in the $7 \mathrm{GHz}$ band, $58^{\circ}$ and $55^{\circ}$ in the $8 \mathrm{GHz}$ band, and $48^{\circ}$ and $42^{\circ}$ in the $9 \mathrm{GHz}$ band. 

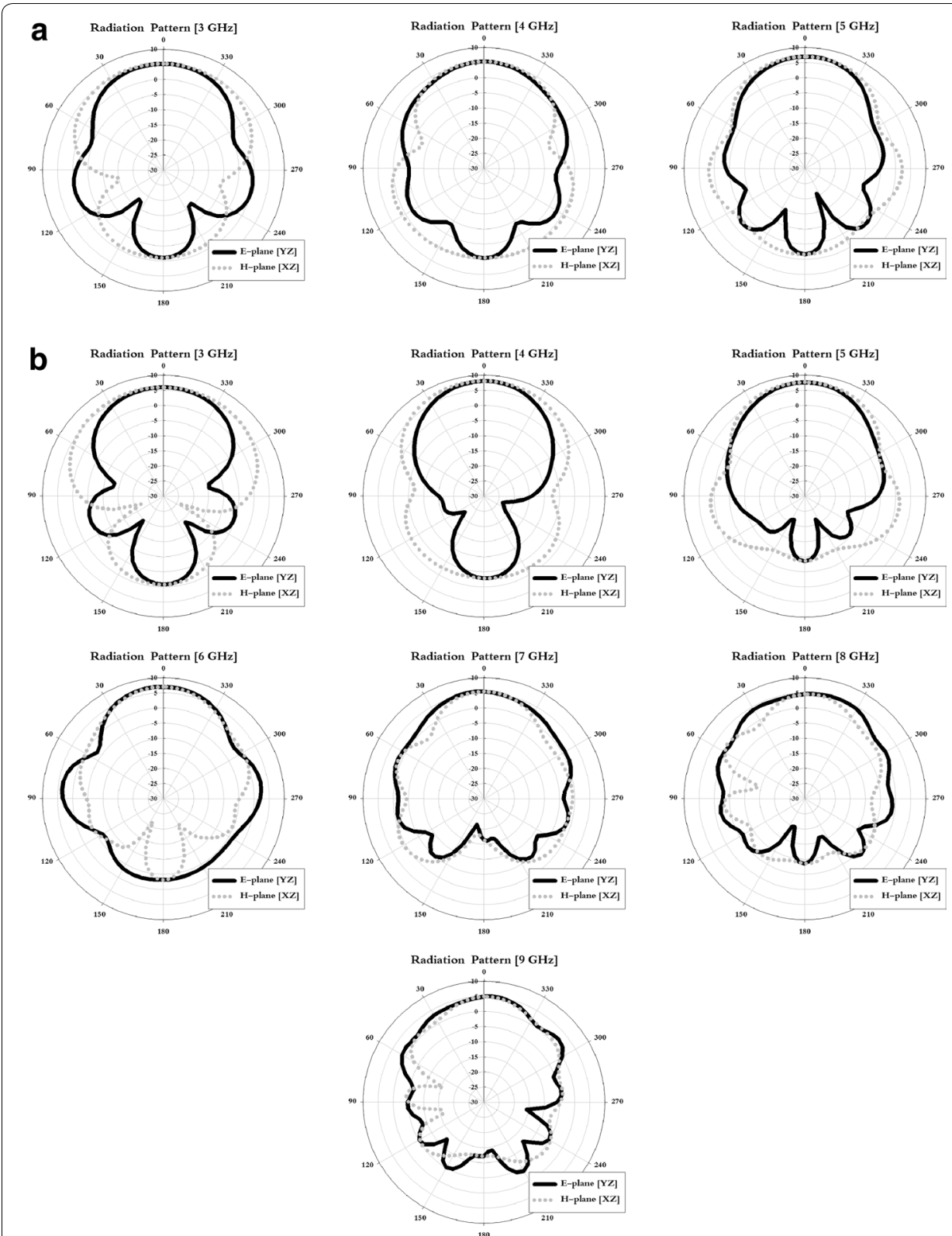

Fig. 6 Results of radiation pattern simulation. a Structure-1. b Structure-2

In the simulation and measurement results, Structure- 1 and Structure- 2 exhibited an approximate 3- $\mathrm{dB}$ beam width. In addition, because of the directive radiation pattern, a characteristic suitable for location recognition in a certain direction was seen.

Based on the radiation pattern analysis, the antenna gain in the proposed bandwidth was analyzed. Figure 8 shows the simulation and measurement results for Structure-1 and Structure-2.

In the simulation results for Structure-1, a gain of $5.15 \mathrm{dBi}$ was seen in the $3 \mathrm{GHz}$ band, $5.37 \mathrm{dBi}$ in the $4 \mathrm{GHz}$ band, and $7.05 \mathrm{dBi}$ in the $5 \mathrm{GHz}$ band. In the case of Structure-2, the gain was $6.06 \mathrm{dBi}$ in the $3 \mathrm{GHz}$ band, $8.12 \mathrm{dBi}$ in the $4 \mathrm{GHz}$ band, $7.6 \mathrm{dBi}$ in the $5 \mathrm{GHz}$ band, $7.12 \mathrm{dBi}$ in the $6 \mathrm{GHz}$ band, $5.56 \mathrm{dBi}$ in the $7 \mathrm{GHz}$ band, $4.91 \mathrm{dBi}$ in the $8 \mathrm{GHz}$ band, 

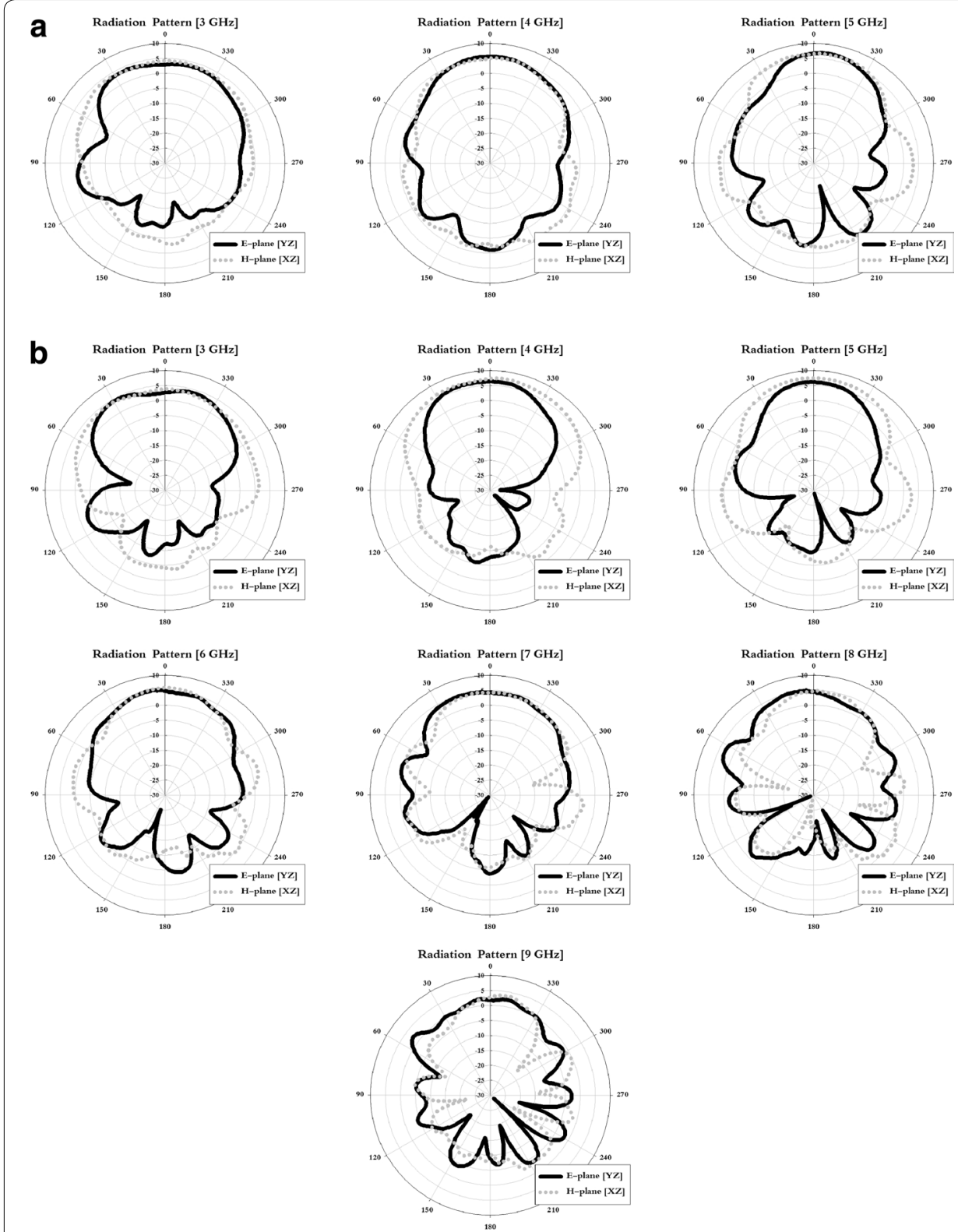

Fig. 7 Results of radiation pattern measurement. a Structure-1. b Structure-2

and $4.93 \mathrm{dBi}$ in the $9 \mathrm{GHz}$ band. In Structure-1, the antenna gain measurement results showed a gain of $3.8 \mathrm{dBi}$ in the $3 \mathrm{GHz}$ band, $5.64 \mathrm{dBi}$ in the $4 \mathrm{GHz}$ band, and $6.91 \mathrm{dBi}$ in the $5 \mathrm{GHz}$ band. In the case of Structure-2, the gain was $4.18 \mathrm{dBi}$ in the $3 \mathrm{GHz}$ band, $7.54 \mathrm{dBi}$ in the $4 \mathrm{GHz}$ band, $7.55 \mathrm{dBi}$ in the $5 \mathrm{GHz}$ band, $5.9 \mathrm{dBi}$ in the $6 \mathrm{GHz}$ band, $4.51 \mathrm{dBi}$ in the $7 \mathrm{GHz}$ band, $4.86 \mathrm{dBi}$ in the $8 \mathrm{GHz}$ band, and $3.57 \mathrm{dBi}$ in the $9 \mathrm{GHz}$ band.

Hence, the proposed antenna's simulation and measurement results for antenna gain were similar.

\section{Comprehensive analysis results for antenna}

Table 2 shows the comprehensive analysis results for the proposed antenna. 


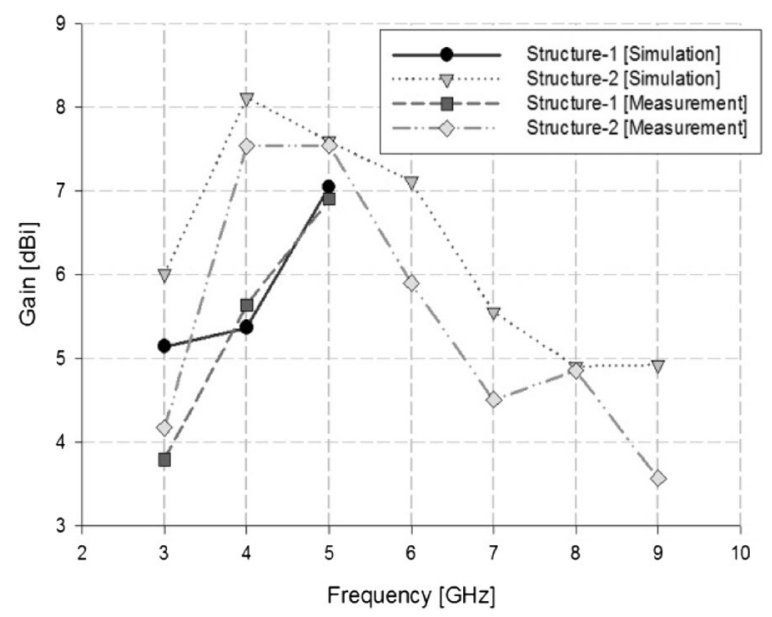

Fig. 8 Antenna gain simulation and measurement results

In Table 2, the antenna impedance bandwidth was improved in Structure-1 compared with Structure-2, and the simulation and measurement results in simulation antenna gain. Furthermore, the total area of the antenna was $4200 \mathrm{~mm}^{2}$ for Structure- 1 and $3550 \mathrm{~mm}^{2}$ for Structure-2. Structure-2 showed a reduction in area of $15.5 \%$ compared with Structure-1. The impedance bandwidth of the antenna was satisfied $-10 \mathrm{~dB}$ S11 and VSWR $\leq 2$, and it shows good impedance matching characteristics.

However, the simulation and measured analysis of the proposed antenna shows the mismatch. A mismatch is considered in the two kinds. The first pertained to loss during the manufacturing process, and the second is a mismatch between the antenna and connector.

The proposed antenna and different antennas are compared in Table 3. The proposed antenna is compact design and it has the wide bandwidth characteristic. This features of

Table 2 Comprehensive analysis results

\begin{tabular}{llll}
\hline & & Simulation & Measured \\
\hline Bandwidth & Structure-1 & $4.13 \mathrm{GHz}$ & $3.73 \mathrm{GHz}$ \\
& Structure-2 & $7.2 \mathrm{GHz}$ & $8.45 \mathrm{GHz}$ \\
$-10 \mathrm{~dB} \mathrm{~S}_{11}$ and VSWR $\leq 2$ & Structure-1 & $2.33-6.46 \mathrm{GHz}$ & $3.26-6.99 \mathrm{GHz}$ \\
& Structure-2 & $3.64-10.84 \mathrm{GHz}$ & $3.55-12 \mathrm{GHz}$ \\
Antenna gain & & & \\
$3 \mathrm{GHz}$ & Structure-1 & $5.15 \mathrm{dBi}$ & $3.8 \mathrm{dBi}$ \\
$4 \mathrm{GHz}$ & Structure-1 & $5.37 \mathrm{dBi}$ & $5.64 \mathrm{dBi}$ \\
$5 \mathrm{GHz}$ & Structure-1 & $7.05 \mathrm{dBi}$ & $6.91 \mathrm{dBi}$ \\
$3 \mathrm{GHz}$ & Structure-2 & $6.06 \mathrm{dBi}$ & $4.18 \mathrm{dBi}$ \\
$4 \mathrm{GHz}$ & Structure-2 & $8.12 \mathrm{dBi}$ & $7.54 \mathrm{dBi}$ \\
$5 \mathrm{GHz}$ & $7.6 \mathrm{dBi}$ & $7.55 \mathrm{dBi}$ \\
$6 \mathrm{GHz}$ & Structure-2 & $7.12 \mathrm{dBi}$ & $5.9 \mathrm{dBi}$ \\
$7 \mathrm{GHz}$ & Structure-2 & $5.56 \mathrm{dBi}$ & $4.51 \mathrm{dBi}$ \\
$8 \mathrm{GHz}$ & Structure-2 & $4.91 \mathrm{dBi}$ & $4.86 \mathrm{dBi}$ \\
$9 \mathrm{GHz}$ & Structure-2 & $4.93 \mathrm{dBi}$ & $3.57 \mathrm{dBi}$ \\
Antenna area & Structure-2 & $4200 \mathrm{~mm}$ & \\
& Structure-1 & $3550 \mathrm{~mm}$ & \\
\hline
\end{tabular}


Table 3 Comparison of the proposed antenna and different antennas

\begin{tabular}{lcc}
\hline Antenna & Impedance bandwidth $\mathbf{( G H z )}$ & Dimensions $\left.\mathbf{~ ( m m ~}^{\mathbf{2}}\right)$ \\
\hline Shao et al. (2013) & $0.64-6$ & $130 \times 70$ \\
Herzi et al. (2016) & $2-5$ & $90 \times 120$ \\
Wang et al. (2016) & $0.65-5.9$ & $220 \times 170$ \\
Proposed antenna & $3.5-12$ & $61 \times 58.2$ \\
\hline
\end{tabular}

proposed antenna of Structure 2 are more detailed in Figs. 3 and 5 which emphases on simulated and experimental results.

\section{Conclusions}

A directive antenna suitable for use as an ultra-wideband tapered slot antenna and for location recognition was designed and proposed. To improve the bandwidth, rectangular slits were inserted in the tapered slot antenna, and the antenna area was reduced. The fabricated rectangular slit-inserted tapered slot antenna exhibited a bandwidth of $8.45 \mathrm{GHz}$ and improved its bandwidth by approximately $4.72 \mathrm{GHz}$. Furthermore, the antenna showed a $15.5 \%$ reduction in area.

The antenna radiation pattern exhibited a beam width of $3 \mathrm{~dB}$ that was suitable for all bandwidths, and a directivity characteristic that was suitable for location recognition in a certain direction. Its highest antenna gain, which was $7.55 \mathrm{dBi}$, was seen in the $5 \mathrm{GHz}$ band.

After these characteristics were comprehensively analyzed, the proposed antenna was shown to be suitable for location recognition in a certain direction owing to its impedance bandwidth characteristic of ultra wideband and its radiation pattern that showed directivity.

\section{Authors' contributions}

SWK involves in design and interpretation of statistical analysis of collected data along with drafting of the manuscript. DYC have been involved for supervision, guidance and critically reviewing manuscript for important intellectual content. Both authors read and approved the final manuscript.

\section{Author details}

1 Department of Information and Communication Engineering, Graduate School of Chosun University, Gwangju, Korea.

2 Department of Information and Communication Engineering, Chosun University, Gwangju, Korea.

\section{Competing of interests}

The authors declare that they have no competing interests.

Received: 19 April 2016 Accepted: 9 August 2016

Published online: 22 August 2016

\section{References}

Chang K (2000) RF and microwave wireless systems. Wiley, New York, pp 74-105

Choi DY, Kim SW, Park JJ, Jeong MA, Lee SR (2014a) Design and implementation of tapered slot antenna for ship's indoor location-aware system. J KICS 39C(12):1307-1313

Choi DY, Shrestha S, Park JJ, Noh SN (2014b) Design and performance of an efficient rectenna incorporating a fractal structure. Int J Commun Syst 27(4):1-19

Deng X, Wang Q Victor G (1999) Structural health monitoring using active sensors and wavelet transform. In: Proceedings of SPIE 1999, smart structures and integrated systems, Newport Beach, vol 3668, pp 363-370

Garg R, Bhartia P, Bahl I, Ittipiboon A (2001) Microstrip antenna design handbook. Artech House, Norwood

He SH, Shan W, Fan C, Mo ZC, Yang FH, Chen JH (2014) An improved vivaldi antenna for vehicular wireless communication system. IEEE Antenna Wirel Propag Lett 13:1505-1508 
Herzi Rabiaa, Zairi Hsan, Gharsallah Ali (2016) Reconfigurable vivaldi antenna with improved gain for UWB applications. Microwave Opt Technol Lett 58:490-494

Kim KY (2013) Design of UWB beam scanning antenna systems based on time domain analysis. Ph.D. thesis, Kwangwon University, Dec. 2013

Kim KJ, Choi WC, Yoon YJ (2015a) Circularly rotated array for dual polarized applicator in superficial hyperthermia system. JEES 15(1):20-25

Kim SW, Kim GS, Noh SK, Choi DY (2015) Design and implementation of an IR-ultra wide band tapered slot antenna with a rectangular slot structure. In: International conference on green and human information technology, pp 321-324

McKinney JD, Peroulis D, Weiner AM (2008) Time-domain measurement of the frequency-dependent delay of broadband antennas. IEEE Trans Antenna Propag 56(1):39-47

Notice of Inquiry in the Matter of Revision of Part 15 of the Commission's Rules Regarding Ultra-Wideband Transmission Systems, FCC Doc. No. 98-208/ET No. 98-153

Peng F, Jiao Y-C, Hu W, Zhang F-S (2011) A miniaturized antipodal vivaldi antenna with improved radiation characteristics. IEEE Antenna Wirel Propag Lett 10:127-130

Pozar DM (2012) Microwave engineering. Wiley, New York, pp 178-188

Shao J, Fang G, Ji YC, Tan K, Yin H (2013) A novel compact tapered-slot antenna for GPR applications. IEEE Antenna Wirel Propag Lett 12:972-975

Shrestha S, Noh SK, Choi DY (2013) Comparative study of antenna design for RF energy harvesting. Int J Antenna Propag 2013:1-10

Wang Y, Zhang F, Fang G, Ji Y, Ye S, Zhang X (2016) A novel ultrawideband exponentially tapered slot antenna of combined electric-magnetic type. IEEE Antenna Wirel Propag Lett 15:1226-1229

Yoon D, Kaynak M, Tillack B, Rieh J-S (2015) A wideband H-band image detector based on SiGe HBT technology. JEES 15(1):59-61

\section{Submit your manuscript to a SpringerOpen ${ }^{\circ}$ journal and benefit from:}

- Convenient online submission

\section{Rigorous peer review}

- Immediate publication on acceptance

- Open access: articles freely available online

- High visibility within the field

- Retaining the copyright to your article

Submit your next manuscript at $\boldsymbol{\nabla}$ springeropen.com 